\title{
How to Design, Modeling, and Analysis of Biomedical Innovations to Develop Creative Solutions for Real-World Medical Problems?
}

\author{
Rajajeyakumar $\mathbf{M}^{1^{\star}}$, Sivakumaran $\mathbf{N}^{2}$, Madanmohan $\mathbf{T}^{3}$ \\ ${ }^{1}$ Department of Physiology, Chennai Medical College Hospital and Research Centre, (SRM Group), Irungalur, Trichy-621105, Tamilnadu, India \\ ${ }^{2}$ Department of Instrumentation and Control Engineering, National Institute of Technology, Trichy-620015, Tamilnadu, India \\ ${ }^{3}$ Department of Physiology, Mahatma Gandhi Medical College \& Research Centre, Pondicherry, India
}

*Corresponding author: Rajajeyakumar M, Department of Physiology, Chennai Medical College Hospital and Research Centre, (SRM Group), Irungalur, Trichy621105, Tamilnadu, India, Tel: 09751382650; E-mail: rajakumar60@gmail.com

Rec date: Feb 26, 2015; Acc date: Feb 27, 2015; Pub date: Mar 06, 2015

Copyright: (c) 2015 Rajajeyakumar M, et al. This is an open-access article distributed under the terms of the Creative Commons Attribution License, which permits unrestricted use, distribution, and reproduction in any medium, provided the original author and source are credited.

\section{Introduction}

Biomedical Engineering science is the combination of the physical and life sciences, incorporating principles from physics and chemistry to understand the functioning of living systems. The overall intellectual goal of biomedical engineering is to apply quantitative engineering analysis to understand the operation of living systems, and to design novel systems to satisfy unmet needs in applied clinical medicine.

\section{How do we prepare researcher to have the right skills and the} right interests?

- Engage their minds and their interest early through rigorous, relevant learning [1]

- Hands-on learning

- Real-world problem solving

- Dedicated, passionate teachers

- Open-ended problems

\section{How to start}

Researcher should decide and choose the topic-based modules in design problems, collaboration, analysis, problem solving, and computational thinking.

\section{Pathway}

Challenging, inspiring, and flexibility will engage researcher natural curiosity and imagination through creative problem solving.

\section{Availability of different independent units as follows}

- Design and Modeling

- Automation and Robotics

- Energy and Environment

- Flight and Space

- Science of Technology

- Medical Detectives

They engage in open-ended problem solving, learn and apply the engineering design process, and develop future skills such as teamwork, communication, and critical thinking.

\section{Importance of biomedical program}

Research students play the roles of biomedical professionals as they investigate and study the concepts of human medicine, physiology, genetics, microbiology, and public health. They engage in activities like investigating the death of a fictional person or dissecting a sheep's heart, learning content in the context of real-world cases. They also examine the structures and interactions of human body systems and explore the prevention, diagnosis, and treatment of disease. Researcher should work collaboratively to understand and design solutions to the most pressing current health challenges [2].

\section{Role of Faculty Development Program}

One of the most unique aspects is the engaging, rigorous professional development activity. Faculty represents a wide variety of backgrounds, but they all share a passion for empowering students with the skills necessary for future success.

\section{Key Competency and Learning Outcomes}

The Biomedical Engineering competency has following learning outcome. Each learning outcome should explain the knowledge, skills, and attitudes of the researcher.

\section{Mathematics}

Biomedical engineers apply mathematics to formulate and solve problems in biology or clinically relevant applications.

\section{Chemistry and Physics}

They should have solid foundations in physics and chemistry which help them to solve complex problems in biology and to further the advancement in health care delivery system.

\section{Biology, Physiology and Anatomy}

Molecular, cellular biology, human physiology, and anatomy provide the foundations for the understanding of the working and maintenance of the human body throughout the life cycle. With such understanding, they can apply their expertise on multiple scales to develop innovations that enhance the quality of life and health care. Examples of their contributions include the development of medical devices, instrumentation, surgical robotics, functional imaging for disease diagnosis and treatment as well as tissue-engineered replacements and pharmaceutical products. 
Citation: Rajajeyakumar M, Sivakumaran N , Madanmohan T (2015) How to Design, Modeling, and Analysis of Biomedical Innovations to Develop Creative Solutions for Real-World Medical Problems?. Bioengineer \& Biomedical Sci 5: 141. doi:10.4172/2155-9538.1000141

Page 2 of 2

\section{Experimentation}

Biomedical engineers must be able to determine the relevance, importance, and societal benefits of the experimental outcomes concerning the medical community.

\section{Structural and design}

Successful design requires critical thinking, an appreciation of the uncertainties involved, and the use of engineering judgment. Consideration of risk assessment, societal and environmental impact, standards, codes, FDA regulations, safety, security, sustainability, constructability, and operability are integrated at various stages of the design process.

\section{Multidisciplinary team}

Multidisciplinary engineering teams are groups of persons engaged in engineering who represent a spectrum of engineering and technical specialties.

\section{Problem based learning}

Problem solving in biomedical engineering consists of identifying engineering problems: understanding technological, Biological, and medical requirements and/or constraints; reviewing available information and literature; proposing and implementing solutions; and, finally, performing evaluation of the results.

\section{Skills, Tools, and Techniques}

Students graduating with an undergraduate degree in biomedical engineering will have the ability to use modern engineering tools, techniques, and processes in the practice of biomedical engineering.

\section{Ethical issue}

Ethical issues are a key component of biomedical engineering today. Ethics relies on the ability to apply moral principles in real-life situations, and it is context-dependent. Particularly today, in the era of genomics there is a need of associated technologies and applications.

\section{Communication skill}

Proficiency in communication includes skills related to listening, observing, reading, speaking, writing, and preparing graphics.

\section{Continuous education}

Biomedical engineers are associated with a wide variety of responsibilities related to human health. While much is known about the human body, a significantly larger portion remains unknown. A continuous learning process, including reading research articles published in peer-reviewed journals, attending conferences, short courses or workshops.

\section{Research interest and specializations}

Biomedical engineers draw upon their engineering knowledge and training in a specific track or specialization to design, evaluate, analyze, solve, and/or develop solutions to a fundamental understanding of human health as well as enhancing diagnosis, monitoring, and therapy. (Biomaterials, Tissue Engineering, Bioinformatics, Biomechanics, Bio imaging, Biosensors, Bioinstrumentations, and Modeling)

\section{Regulatory bodies}

Biomedical researcher must consider strategic, tactical, and operational direction and support for working within regulations to expedite the development and delivery of safe and effective healthcare products to individuals around the world.

\section{Contemporary issues and impact of engineering solutions}

Contemporary issues at local and global scales must be integrated into the design and implementation of biomedical solutions. The need for inexpensive diagnostic and treatment methodologies in developing countries is an important contemporary societal need. The biomedical engineers should be trained to consider such issues during the design and implementation of medical technologies.

With the high degree of globalization, it is also extremely important for biomedical engineers to assess health, sanitation, sustainability, development, supply chain, competitiveness, production, and environmental effects on a global scale to perform their functions effectively. Obtaining such awareness skills involves continuous learning and interaction on a global scale. Some of the methods by which students can gain these skills include group problem solving of real medical challenges, study abroad and exchange-student options, and working trips to developing countries to obtain knowledge of contemporary issues, medical challenges, and needs of those countries [3]. Students should have the knowledge to access the strong research infrastructure including a wide variety of core facilities, experts in biostatistics, bioinformatics and develop a platform to apply engineering knowledge to health care and medical research [4].

\section{References}

1. Project Lead the Way High School Programs: Engineering Biomedical Science Computer Science.

2. Hotaling N, Fasse BB, Bost LF, Hermann CD, Forest CR (2012) A Quantitative Analysis of the Effects of a Multidisciplinary Engineering Capstone Design Course. Journal of Engineering Education 101: 630-656.

3. Tuning of Biomedical Engineering (2012) Lumina Foundation for Education, Texas Higher Education Coordinating Board, Austin, Texas.

4. Rajajeyakumar M, Bhattacharjee M, Sharma VK, Alagarsamy J (2015) Integrative Approach to Multidisciplinary Training in Physiology and Biomedical Engineering. J Bioengineer \& Biomedical Sci 5: 1-2. 